\title{
Hemodynamic assessment of Perceval sutureless bioprosthesis by dobutamine stress echocardiography
}

Running head: Hemodynamics of Perceval sutureless valve

Antonino S. Rubino, ${ }^{a, d} M D$ PhD, Fausto Biancari, ${ }^{b, f, g} M D$ PhD, Vincenzo Caruso, ${ }^{a} M D$, Vincenzo Lavanco, ${ }^{c} M D$, Fiorella Privitera, ${ }^{c}$ MD, Ivana Rinaldi, ${ }^{c}$ MD, Maria Sanfilippo, ${ }^{c} M D$, Giovanni Millan, ${ }^{c}$ MD, Lucia V. D'Urso, ${ }^{c}$ MD, Sergio Castorina, ${ }^{d, e}$ MD FACS, Carmelo Mignosa, ${ }^{a, d}$ MD FECTS

${ }^{a}$ Cardiac Surgery Unit, A.O.U. "Policlinico-Vittorio Emanuele”, Ferrarotto Hospital, University of Catania, Italy

${ }^{b}$ Heart Center, Turku University Hospital, Turku, Finland

${ }^{c}$ Cardiology Unit, A.O.U. “Policlinico-Vittorio Emanuele”, Ferrarotto Hospital, University of Catania, Italy

${ }^{d}$ Fondazione “G.B Morgagni”, Heart Center, Pedara (CT), Italy

${ }^{e}$ Department of Biomedical and Biotechnological Sciences, University of Catania, Italy

${ }^{f}$ Department of Surgery, University of Turku, Turku, Finland

${ }^{g}$ Department of Surgery, University of Oulu, Oulu, Finland.

Text word count: 5012 words

Disclosures: ASR received a research grant from Sorin Group. CM is consultant for LivaNova Biomedica Cardio Srl.

\section{Corresponding author:}

Antonino S. Rubino, MD

Department of Cardiology and Cardiovascular Surgery

Fondazione "G.B. Morgagni"

Heart Center

Via della Resistenza, 31

95030 Pedara (CT), Italy

Tel.+39095 7026186

Fax +39095 915161

E-mail: antonio.rubino@hotmail.com 


\section{AUTHOR CONTRIBUTION}

Antonino S. Rubino: Concept/design, Data analysis/interpretation, Drafting article, Statistics

Fausto Biancari, Lucia V. D’Urso, Carmelo Mignosa, Sergio Castorina: Critical revision of the article

Vincenzo Caruso, Fiorella Privitera, Ivana Rinaldi, Maria Sanfilippo: Data collection

Giovanni Millan, Vincenzo Lavanco: Data collection and final approval of echocardiographic parameters. 


\section{ABSTRACT}

Objectives: The aim of this study was to evaluate the hemodynamic performance of a sutureless bioprosthesis under high workload at mid-term follow-up.

Methods: Thirty-two patients who underwent isolated aortic valve replacement with a Perceval sutureless bioprosthesis with a minimum follow-up of 1 year were enrolled in this study. A S size prosthesis was deployed in 10 patients $(31.3 \%)$, , M size in $9(28.1 \%)$, a L size in $8(25 \%)$ and a XL size in 5 (15.6\%). Effective orifice area (EOA), EOA index (EOAi) and transvalvular gradients were assessed at rest and during dobutamine stress echocardiography (DSE) a median of 19.5 months after surgery.

Results: DSE significantly increased heart rate, stroke volume, ejection fraction and transvalvular gradients (peak gradient, $24.0 \pm 7.6$ vs $38.7 \pm 13.6 \mathrm{mmHg}, \mathrm{p}<0.001$; mean gradient, $12.6 \pm 4.2$ vs $19.8 \pm 8.3, \mathrm{p}<0.001)$. When compared to baseline, estimated valve areas significantly increased at follow-up (EOA, $1.48 \pm 0.46$ vs $2.06 \pm 0.67, \mathrm{p}<0.001$; EOAi, $0.84 \pm 0.26$ vs $1.17 \pm 0.37, \mathrm{p}<0.001)$. Mean percentage increase of EOAi was $40.3 \pm 28.0 \%$. S size prostheses had the highest increase in EOA1, but the difference was not significant ( $\mathrm{S} 46.0 \pm 27.5 \%$ vs. M $45.4 \pm 34.5 \%$ vs. L $32.7 \pm 26.4 \%$ vs XL $32.1 \pm 20.5 \%, \mathrm{p}=0.66)$. Severe patient-prosthesis mismatch $\left(\mathrm{EOAi} \leq 0.65 \mathrm{~cm}^{2} / \mathrm{m}^{2}\right)$ was present at rest in 8 patients (25\%), but only in one patient (3.1\%) during DSE.

Conclusions: The Perceval sutureless bioprosthesis demonstrated good hemodynamics at rest and under high workload. The significant increase of EOAi during DSE suggests the potential advantages of Perceval sutureless bioprostheses in case of small aortic annulus or when patient-prosthesis mismatch is anticipated.

Keywords: Aortic valve prosthesis; sutureless; dobutamine stress echocardiography; aortic valve replacement Abstract word count: 248 words 


\section{INTRODUCTION}

Aortic valve replacement (AVR) is the gold standard therapy for severe symptomatic aortic stenosis. However, with the aging of the population and the improvement of medical therapy, patients have significant comorbidities which increases the operative risk. Sutureless aortic valve bioprostheses have been developed to overcome the inherent increased risk of surgical AVR by reducing the aortic cross-clamping time. The Perceval sutureless bioprosthesis (LivaNova Biomedica Cardio Srl, Saluggia, Italy) demonstrated excellent immediate results in patients at intermediate operative risk [1-3]. However, hemodynamics of this valve prosthesis have been described in vivo only at rest and, to the best of our knowledge, there are no data on the hemodynamic performance of Perceval sutureless bioprosthesis under high workload conditions at mid-term follow-up. We sought to compare follow-up echocardiographic findings of Perceval sutureless bioprosthesis to preoperative and discharge records, and to evaluate the valve hemodynamics at rest and under stress at mid-term follow-up. 


\section{METHODS}

From April 2011 to June 2015, a Perceval sutureless bioprosthesis (LivaNova Biomedica Cardio Srl, Saluggia, Italy) was implanted in 106 consecutive patients with a preoperative diagnosis of severe symptomatic aortic stenosis with or without associated aortic regurgitation of any grade. Other major concomitant cardiac procedures (coronary surgery, septal myectomy, mitral valve repair, tricuspid valve repair) were performed when needed.

Indications for the implantation of a sutureless bioprosthesis were as follows: elderly patients with multiple comorbidities, frailty and increased operative risk as estimated by EuroSCORE II score; patients with small annulus and/or calcified aortic root [4]. Preoperative patient's frailty was graded according to the CSHA scale [5]. The implantation of this valve was considered feasible when the aortic annulus size was between $19 \mathrm{~mm}$ and 27 $\mathrm{mm}$ and ratio between the sinotubular diameter and that of the aortic annulus was less than 1.3 [1]. According to manufacturer's instruction, $\mathrm{S}$ size fits in an annulus diameter ranging from 19 and $21 \mathrm{~mm}, \mathrm{M}$ between 21-23 mm, L between 23-25 mm and XL between 25-27 mm. However, in vitro simulations demonstrated that size $\mathrm{S}$ can fit in a range 17.5-19.0 mm, M 19.5-21.0 mm, L 21.5-23 mm and XL 23.5-25 mm [Clinical Atlas of Transcatheter Aortic Valve Therapies (Valve in Valve Aortic App)].

Preoperative annular and root dimensions were measured routinely with trans-thoracic echocardiography in all patients. ECG-gated angioCT scan of the aortic root were performed only when minimally invasive procedures were scheduled. Intraoperative trans-esophageal echocardiography confirmed preoperative dimensions in all patients and allowed assessing the correct positioning and function of the implanted prosthesis.

The technique of implantation has been previously described [1]. In all patients, the aortic annulus was completely decalcified. No attempt to enlarge the annulus has been made, according to the manufacturer's instruction. The annulus was measured with appropriate sizers and the valve size was chosen according to intraoperative measurements. Three 4-0 polypropylene guiding sutures were passed at the nadir of each sinus and then inside the green eyelets to help parachuting the prosthesis valve in the correct position. Once the prosthesis valve was in place, it was ballooned at 4 atmospheres for 30 seconds while the field was rinsed with warm saline [1].

Institutional Review Board approved the study and informed consent was obtained form each patient. Since this patient population included mainly elderly and fragile patients, who were unable to adequately perform an exercise 
protocol, we decided to perform a pharmacological stress instead of a physical test in order to avoid any potential bias regarding the inability to conclude the test due to muscular fatigue. Accordingly, dobutamine stress echocardiography (DSE) was used to investigate the hemodynamics of the Perceval sutureless bioprosthesis. The enrollment of patients for the echocardiographic follow-up started in December 2014 and ended in May 2015. To avoid any bias, we selected patients who have undergone isolated AVR and with a follow-up of at least 1 year. Patients with left ventricular ejection fraction $\leq 30 \%$, mitral insufficiency, conduction disturbances, arrhythmias, or a known contraindication to dobutamine stress test were excluded from the study. Thirty-two patients were enrolled for DSE exam and their baseline demographics and echocardiographic details are summarized in Table 1. Details from a cohort of patients undergone AVR with stented bioprostheses during the study period has been also reported, as a means of portraying the risk profile of the study group.

Patients were recommended to discontinue beta-blockers at least five days before the study as well as ACEinibitors and/or calcium antagonists 48 hours before [6]. Dobutamine infusion started at $5 \mathrm{mcg} / \mathrm{kg} / \mathrm{min}$ and the dose was increased every 5 minutes by $5 \mathrm{mcg} / \mathrm{kg} / \mathrm{min}$ interval until $75 \%$ of the expected maximal heart rate was reached (calculated with the Karvonen's formula as 220 - age), or to a maximal dose of $40 \mathrm{mcg} / \mathrm{kg} / \mathrm{min}$, to assess valve hemodynamics under the hypothetical setting of the maximal tolerated workload. During the study, patients underwent continuous electrocardiographic monitoring and blood pressure was measured every 5 minutes with an automated device.

The criteria to discontinue the test before reaching the expected maximal heart rate were the following: systolic blood pressure $<100 \mathrm{mmHg}$, dyspnea, any ventricular or supraventricular arrhythmia, and/or angina-like symptoms [7].

LVOT measurements were recorded preoperatively, at hospital discharge and at rest before starting the DSE protocol. Gradients and velocities were recorded at rest and at maximal cardiac output according to Zoghbi et al.[8]. All images were recorded using a General Electric Vivid E9 (GE Health Medical, Horten, Norway) and stored in EchoPAC (GE Health Medical, Horten, Norway) for further analysis. Peak and mean transvalvular gradients were calculated according to the modified Bernoulli equation, whereas the effective orifice area (EOA) and the effective orifice area index (EOAi) were estimated with the continuity equation. Dimensionless Velocity Index (DVI) was calculated as the ratio of velocity-time integrals in left ventricular outflow tract (pulsed wave 
Doppler) and across the valve (continuous wave Doppler). A DVI $<0.25$ suggested a severe aortic stenosis. An EOAi $\leq 0.65 \mathrm{~cm} 2 / \mathrm{m} 2$ was considered suggestive of severe prosthesis-patient mismatch (PPM), according to Pibarot et al. [9].

At the end of the test, dobutamine infusion was discontinued and patients were monitored for at least 20 minutes or until heart rate returned to pre-test values.

All measurements were recorded by a single senior consultant of cardiology (GM) throughout the study period and were further reviewed by an experienced echocardiographer (VL), to corroborate valve gradients and valve area calculations.

Statistical analysis was performed using IBM SPSS Statistics for Windows, Version 20.0 (Armonk, NY; IBM Corp). The normality distribution of the difference between recordings at rest and under DSE was checked with the Kolmogorov-Smirnov test. Continuous variables are presented as mean \pm standard deviation (SD), and categorical variables are presented as absolute numbers and/or percentages. Comparisons between groups were performed using independent-sample $t$-test, Chi-square test, Mann-Whitney $U$-test and Kruskal-Wallis testwhere appropriate. Differences between measured parameters at rest and at maximal exercise were assessed with paired sample $t$-test or Wilcoxon signed rank test where appropriate. Differences in categorical variables were evaluated using the the McNemar test. For all test, a p-value $<0.05$ was considered statistically significant. 


\section{RESULTS}

Transvalvular gradients and valve area at discharge significantly improved compared to preoperative values (peak gradient $81.0 \pm 24.1$ vs $22.9 \pm 9.4$; mean gradient $48.6 \pm 18.0$ vs $12.6 \pm 5.5$; AVA $0.7 \pm 0.2$ vs $1.5 \pm 0.2$; AVAi $0.38 \pm 0.15$ vs $0.85 \pm 0.14$; all $\mathrm{p}<0.001$ ). However, 4 patients presented an EOAi $\leq 0.65 \mathrm{~cm}^{2} / \mathrm{m}^{2}$ at discharge.

All patients were in NYHA functional class I-II after a median follow-up of 19.5 months (IQR 15.3-27.3). At midterm echocardiographic control, peak and mean gradients (peak gradient 22.9 \pm 9.4 vs 24.0 $\pm 7.6, p=0.45$; mean gradient $12.6 \pm 5.5$ vs $12.6 \pm 4.2, \mathrm{p}=0.87$ ) as well as valve areas (EOA $1.5 \pm 0.2$ vs $1.5 \pm 0.5, \mathrm{p}=0.82$; AVAi $0.85 \pm 0.14$ vs $0.84 \pm 0.26, \mathrm{p}=0.91$ ) were similar to those observed at discharge. LVOT diameters did not change significantly between measurements (preoperative $19.8 \pm 1.6$ vs discharge $20.0 \pm 1.2$ vs rest at follow-up $19.9 \pm 1.4 \mathrm{~mm} ; \mathrm{p}=0.56$ ). Patients in NYHA functional class II had similar gradients compared to patients in NYHA functional class I (peak gradient $23.5 \pm 7.5$ vs $24.4 \pm 7.8 \mathrm{mmHg}, \mathrm{p}=0.69$; mean gradient $12.5 \pm 4.1$ vs $12.6 \pm 4.4, \mathrm{p}=0.90$ ).

EOAi was $\leq 0.65 \mathrm{~cm}^{2} / \mathrm{m}^{2}$ in eight patients $(25 \%$ ), without any difference in terms of NYHA functional class $(1.6 \pm 0.5$ vs. $1.4 \pm 0.5, \mathrm{p}=0.31)$.

All patients were able to complete the test without adverse events (Table 2). Heart rate and stroke volume significantly increased with DSE. At maximal stress, peak and mean transvalvular gradients significantly increased from baseline, but never reaching a mean gradient of $40 \mathrm{mmHg}$, which is a cutoff suggestive of an iatrogenic aortic stenosis.

Similarly, EOA, EOAi (Fig. 1) and DVI increased significantly. Mean percentage increase of EOAi was $40.3 \pm 28.0 \%$. When stratified accordingly to valve size, $\mathrm{S}$ size valves showed the highest percentage increase, but such a difference did not reach statistical significance (S $46.0 \pm 27.5 \%$ vs M $45.4 \pm 34.5 \%$ vs L $32.7 \pm 26.4 \%$ vs XL $32.1 \pm 20.5 \%$; $\mathrm{p}=0.66$ ). Similarly, the mean percentage increase of DVI was $40.9 \pm 28.7 \%$ without statistical significance between different valve sizes (S $47.2 \pm 28.7 \%$ vs M $45.8 \pm 30.1 \%$ vs L $32.0 \pm 25.1 \%$ vs XL $33.4 \pm 21.3 \%$; $\mathrm{p}=0.60$ at Kruskal-Wallis test). The observed trends of transvalvular gradients were confirmed when results were stratified according to the valve size (Tab. 3).

When eight patients with an EOAi $\leq 0.65 \mathrm{~cm}^{2} / \mathrm{m}^{2}$ were considered, criteria for severe PPM was observed only in one patient (3.1\%) at maximal pharmacological stress. Accordingly, a significant increase of EOA and EOAi was 
observed, without increased gradients suggestive of valve dysfunction (Table 4). 


\section{DISCUSSION}

Assessment of prosthetic valve function is usually performed at rest after AVR. However, increasing gradients under high workload conditions is not an uncommon finding, particularly in case of narrow aortic annuli, unless aortic annular enlargement is performed [10,11]. Accordingly, exercise echocardiography or DSE may unveil a prosthetic valve dysfunction otherwise overlooked at rest.

Several reports confirmed the equipoise of both techniques for the hemodynamic evaluation of aortic valve prosthesis $[12,13]$. However, the aim of this study was to assess valve hemodynamics at increased workload, independently from the occurrence of dyspnea during physical exercise. Accordingly, in the present study, we preferred the DSE to exercise test, to avoid the potential bias of an incomplete exercise test. Besides the the inherent benefits of reducing aortic cross-clamping time, Perceval sutureless bioprosthesis became the valve of choice for elderly, fragile patients at our institution (Tab. 1).

The reliability of the Perceval sutureless bioprosthesis for aortic valve replacement has been already demonstrated [1-3]. Initially, this valve prosthesis was implanted mostly in very elderly or in those patients with severe comorbidities. Indeed, patients enrolled in the present study were older, more fragile, with a higher expected operative risk compared to a contemporary cohort of patients receiving stented valve. Later on, the use of this bioprosthesis was found valuable in minimally invasive surgery also in lower risk patients [14-16].

When valve performance at rest is concerned, we observed similar results compared to other recently studies, either in terms of peak and mean gradients or EOA [17,18] also when compared to a propensity-matched cohort of patients undergoing TAVI [19]. On the other hand, we observed slightly higher gradients in our multicenter European cohort of patients undergone AVR with Perceval sutureless bioprosthesis compared to a multicenter TAVI Italian experience (ITER registry) [20]. Therefore, a hemodynamic comparison between Perceval sutureless bioprosthesis and TAVI is still a matter of concern and further studies are needed to confirm these results.

Because of the widespread use of this valve bioprosthesis, particularly in an increasing number of physically active patients, the assessment of its hemodynamic performance under high workload conditions is of clinical relevance. In the present study, we observed increased transvalvular gradients during DSE as a result of increased heart rate and stroke volumes. This is a general finding when the performances of aortic prostheses are investigated under 
stress. Offstad et al. [21] reported a 134\% increase in mean transvalvular gradients at peak stress in a cohort of patients receiving mechanical prostheses. Similarly, Minardi assessed the hemodynamic of 19 patients receiving small sized 17-mm St. Jude Medical Regent mechanical prostheses. Interestingly, despite a significant improvement in functional classes at $36 \pm 12$ month follow-up, most of patients developed at least mild PPM, with significant increase of mean prosthetic gradients, reaching an average of $42.3 \pm 12.7 \mathrm{mmHg}$. [22]. Increasing transvalvular gradients under DSE have been reported also by Sezai et al. [23] on 58 patients undergone AVR with all sizes of St. Jude Medical Regent prosthesis. In particular, $10.3 \%$ of patients have PPM without clinical significance in the early and mid-term follow-up [23].

Interestingly, Khoo et al. [24] reported on the hemodynamic better performance of stentless over stented prostheses. These authors showed that stentless valve prostheses perform similarly to mildly stenosed native aortic valves under stress, whereas stented and mechanical prostheses resembled the performances of mild-to-moderate stenosis. Repossini et al. [25] described an increase in mean transvalvular gradients during exercise in patients undergone AVR with the Freedom SOLO bioprosthesis. These results are in part expected, because a mechanical valve cannot accommodate larger stroke volumes, therefore resulting in increased gradients. On the other hand, bioprostheses can modulate leaflet motion according to stroke volumes, thus resulting in increased EOA with only slight rise in transprosthetic gradients.

In the present study, we observed a significant increase in EOA, EOAi and DVI under stress. This is in contrast with the findings of Silberman et al. [26], who failed to detect any differences in EOAi under stress for stented, stentless bioprostheses and mechanical valves. On the other hand, Hanke and coworkers reported increased EOAi in patients undergone exercise stress after AVR with Trifecta stented bioprosthesis, Ross operation and in a control group of healthy volunteers, but not in those patients who received a stentless Freestyle valve [27]. Similarly, Bach and associates demonstrated similar hemodynamics at rest and during exercise between stented Trifecta and stentless Freedom bioprostheses, being both valves superior to Magna Ease in terms of peak velocity, mean gradient and EOA [28]. Furthermore, Repossini et al. [25] reported an increase in EOA from $1.7 \pm 0.3 \mathrm{~cm}^{2}$ to $1.8 \pm 0.4 \mathrm{~cm}^{2}$ at exercise stress echocardiography. When these last results are compared with the findings of our study, we observed a significantly greater increase of EOA at DSE, reaching $2.1 \pm 0.7 \mathrm{~cm}^{2}$ at peak stress. These findings should be viewed in light of technical and methodological differences between these studies. First, 
although exercise and dobutamine stress test are equivalently effective for the evaluation of aortic valve prostheses, the two methodologies are not fully comparable $[12,13]$. Second, despite a similar valve prosthesis profile, the Freedom Solo is a complete supra-annular stentless valve seated on the Valsalva sinuses, whereas the Perceval sutureless bioprosthesis is deployed in to the native aortic annulus and this might be responsible for different hemodynamics. It could be speculated that the nitinol struts might be responsible of increased transvalvular gradients at rest. However, we recorded a mean transvalvular gradient of $12.6 \pm 4.2 \mathrm{mmHg}$ at rest, with an EOA of $1.5 \pm 0.5 \mathrm{~cm}^{2}$. Interestingly, Tasca et al. [29] demonstrated that small size sutureless valve provided lowest gradients and larger EOA in an in vitro study, compared to two standard pericardial stented bioprostheses. These results have been confirmed clinically by Shresta et al. [20], who observed a mean gradient of $13.6 \pm 5.4 \mathrm{~cm}^{2}$ and an EOA of $1.5 \pm 0.25 \mathrm{~cm}^{2}$ in a cohort of elderly patients with preoperative annulus $\leq 22 \mathrm{~mm}$. Similarly, Dedeilias et al. [31] reported the results in elderly patients with a BSA $<2 \mathrm{~m}^{2}$ undergoing AVR with Perceval sutureless bioprosthesis or stented bioprosthesis. Interestingly, they recorded significantly greater EOA in the sutureless valve prosthesis group (1.5 \pm 0.3 vs $\left.1.1 \pm 0.5 \mathrm{~cm}^{2} ; \mathrm{p}=0.002\right)$ [31]. Furthermore, Shalabi demonstrated that the Perceval sutureless bioprosthesis is associated to improved hemodynamic performance when compared to stented valves in a selected group of elderly patients with annulus diameter $\leq 21 \mathrm{~mm}$ (peak gradients, $15 \pm 7$ vs. $20 \pm 11 \mathrm{mmHg}, \mathrm{p}=0.02$; EOAi, $1.12 \pm 0.2$ vs. $\left.0.82 \pm 0.1 \mathrm{~cm}^{2} / \mathrm{m}^{2}, \mathrm{p}<0.05\right)[32]$.

It could be speculated from our study that leaflet dynamic is not impaired by the nitinol stent, as demonstrated by the increased EAOi both at rest and at peak stress. This might suggest that the Perceval sutureless bioprosthesis could be considered almost as a stentless valve, with inherent better hemodynamics in small aortic annuli [30].

These findings were observed for any given valve prosthesis size, with the largest percentage increase for the $\mathrm{S}$ size, despite this difference did not reaching statistical significance. This finding becomes relevant especially in patients with an EOAi $\leq 0.65 \mathrm{~cm}^{2} / \mathrm{m}^{2}$ at rest. In fact, seven out of eight patients with PPM significantly increased EOAi during DSE. Accordingly, Villa et al. [33] recently demonstrated the satisfying performance of the S size Perceval sutureless bioprosthesis either at discharge or at early follow-up, further validating the excellent hemodynamic performance of the sutureless bioprosthesis in patient with small aortic annuli [30,32]. These results suggest that the reliability of Perceval sutureless bioprosthesis even in patients with a small aortic annulus, or when a PPM could be anticipated preoperatively. Furthermore, Blais et al. [11] demonstrated that mild-to-moderate PPM 
is not always an issue of clinical relevance. Finally, the Perceval sutureless bioprosthesis could be a valuable option for for those patients with calcified aortic root, in whom any attempt to enlarge the annulus may endanger the outcome of these patients [4,34].

A number of limitations related to this study should be acknowledged. First, the small sample size of this series is a clear limitation of this study. On the other hand, our results stem from the single-center design of the study, which guarantees uniformity of the surgical technique and of echocardiographic evaluations. Furthermore, in an attempt to better validate our hypothesis, we selected patients with at least one-year follow-up in order to test also the hemodynamic performance of this valve prosthesis late after surgery. Second, the flow dependence of the EOA estimated by the continuity equation could be considered controversial, as the increased EOA might be the result of a mathematical effect without any anatomical implication. However, one of the major strength of this analysis is the strict inclusion criteria of these the patients. In particular, the exclusion of patients with severe left ventricular systolic dysfunction and/or mitral valve regurgitation prevented any bias of Doppler quantifications. Finally, the lack of a control group with stented bioprostheses, prevents conclusive results on the hemodynamic benefits of the Perceval sutureless bioprosthesis in patients with small aortic annulus. 
In conclusion, AVR with the Perceval sutureless bioprosthesis provides excellent hemodynamics at rest and under DSE. The significant increase of EOAi under DSE suggests the potential benefit of using the Perceval sutureless bioprosthesis in patients with small aortic annulus or when PPM is anticipated. 


\section{Legend to figure}

Figure 1. Variation of effective orifice area index (EOAi) under exercise. Dashed line is set at $0.65 \mathrm{~cm}^{2} / \mathrm{m}^{2}$ as the threshold for severe prosthesis-patient mismatch 
Table 1. Baseline characteristics, preoperative echocardiographic and intraoperative details

\begin{tabular}{|c|c|c|c|}
\hline & Perceval & Conventional & \\
\hline & $\mathrm{n}=32$ & $\mathrm{n}=87$ & $\mathbf{p}$ \\
\hline Age at surgery (years) & $74.6 \pm 5.6$ & $62.8 \pm 14.1$ & $<0.001$ \\
\hline Gender (F) & $18(56.3 \%)$ & $45(51.7 \%)$ & 0.66 \\
\hline Height (m) & $160.7 \pm 8.1$ & $162.5 \pm 8.9$ & 0.32 \\
\hline Weight (Kg) & $70.1 \pm 13.3$ & $71.1 \pm 14.5$ & 0.73 \\
\hline Body surface area $\left(\mathrm{m}^{2}\right)$ & $1.76 \pm 0.18$ & $1.78 \pm 0.21$ & 0.59 \\
\hline Body mass index $\left(\mathrm{Kg} / \mathrm{m}^{2}\right)$ & $27.2 \pm 5.2$ & $26.9 \pm 4.91$ & 0.74 \\
\hline eGFR classes & & & 0.04 \\
\hline$>85 \mathrm{ml} / \mathrm{min} / \mathrm{m}^{2}$ & $3(9.4 \%)$ & $34(39.1 \%)$ & \\
\hline $50-85 \mathrm{ml} / \mathrm{min} / \mathrm{m}^{2}$ & $21(65.6 \%)$ & $44(50.6 \%)$ & \\
\hline$<50 \mathrm{ml} / \mathrm{min} / \mathrm{m}^{2}$ & $8(25 \%)$ & $9(10.3 \%)$ & \\
\hline Extracardiac arteriopathy & $4(12.5 \%)$ & $4(4.6 \%)$ & 0.13 \\
\hline Poor mobility & $1(3.1 \%)$ & 0 & 0.10 \\
\hline Redo & $2(6.3 \%)$ & $7(8.0 \%)$ & 0.74 \\
\hline Chronic lung disease & $5(15.6 \%)$ & $16(18.4 \%)$ & 0.73 \\
\hline IDDM & $6(18.8 \%)$ & $7(8.0 \%)$ & 0.10 \\
\hline NYHA III-IV & $24(75 \%)$ & $58(66.7 \%)$ & 0.38 \\
\hline LVEF & $57.3 \pm 8.1 \%$ & $57.1 \pm 8.1$ & 0.90 \\
\hline LVEF classes & & & 0.46 \\
\hline$>50 \%$ & $25(78.1 \%)$ & $73(83.9 \%)$ & \\
\hline $30-50 \%$ & $7(21.9 \%)$ & $14(16.1 \%)$ & \\
\hline PAPs (mmHg) & $31.9 \pm 7.9$ & $33.3 \pm 8.2$ & 0.42 \\
\hline PAPs classes & & & 0.76 \\
\hline$<30 \mathrm{mmHg}$ & $15(46.9 \%)$ & $38(43.7 \%)$ & \\
\hline
\end{tabular}




\begin{tabular}{|c|c|c|c|}
\hline $31-55 \mathrm{mmHg}$ & $17(53.1 \%)$ & $49(56.3 \%)$ & \\
\hline EuroSCORE II & $4.16 \pm 3.47 \%$ & $2.38 \pm 2.40 \%$ & 0.002 \\
\hline CSHA scale & $3.3 \pm 0.6$ & $2.1 \pm 0.7$ & $<0.001$ \\
\hline Annulus (mm) & $22.2 \pm 1.8$ & $21.8 \pm 1.8$ & 0.37 \\
\hline Annulus $\leq 21 \mathrm{~mm}$ & $8(25.0 \%)$ & & \\
\hline Sinuses of Valsalva (mm) & $30.0 \pm 2.9$ & - & - \\
\hline Sino-tubular junction (mm) & $26.6 \pm 2.3$ & - & - \\
\hline Aortic root height (mm) & $17.7 \pm 2.6$ & - & - \\
\hline Peak gradient $(\mathrm{mmHg})$ & $81.0 \pm 24.1$ & $80.0 \pm 14.5$ & 0.78 \\
\hline Mean gradient $(\mathrm{mmHg})$ & $48.6 \pm 18.0$ & $50.1 \pm 11.2$ & 0.62 \\
\hline Associated aortic regurgitation $\geq 3+$ & $2(6.25 \%)$ & $4(4.6 \%)$ & 0.72 \\
\hline $\operatorname{AVA}\left(\mathrm{cm}^{2}\right)$ & $0.7 \pm 0.2$ & $0.7 \pm 0.1$ & 0.39 \\
\hline $\operatorname{AVAi}\left(\mathrm{cm}^{2} / \mathrm{m}^{2}\right)$ & $0.38 \pm 0.15$ & $0.39 \pm 0.08$ & 0.55 \\
\hline Surgical approach & & & 0.83 \\
\hline Full sternotomy & $18(52.2 \%)$ & $40(46.0 \%)$ & \\
\hline $\mathrm{J}$ mini-sternotomy & $14(43.8 \%)$ & $47(56.0 \%)$ & \\
\hline Aortic cross-clamping time (min) & $34.7 \pm 10.8$ & $77.7 \pm 36.5$ & $<0.001$ \\
\hline Cardiopulmonary bypass time (min) & $58.5 \pm 15.9$ & $110.5 \pm 43.5$ & $<0.001$ \\
\hline \multicolumn{4}{|l|}{ Size } \\
\hline $\mathrm{S}$ & $10(31.3 \%)$ & - & - \\
\hline M & $9(28.1 \%)$ & - & - \\
\hline $\mathrm{L}$ & $8(25 \%)$ & - & - \\
\hline XL & $5(15.6 \%)$ & - & - \\
\hline
\end{tabular}

eGFR: estimated glomerular filtration rate; IDDM: insulin-dependent diabetes mellitus; NYHA: New York Heart Association; LVEF: left ventricular ejection fraction; PAPs: pulmonary artery pressure systolic; EuroSCORE: European System for Cardiac Operative Risk Evaluation; AVA(i): aortic valve area (index). 
Table 2. Hemodynamic assessments during dobutamine stress echocardiography

\begin{tabular}{|c|c|c|c|}
\hline & Rest & Exercise & $\mathbf{p}$ \\
\hline Heart rate & $71.0 \pm 10.5$ & $119.0 \pm 11.0$ & $<0.001$ \\
\hline Stroke volume (ml) & $69.1 \pm 14.2$ & $90.1 \pm 17.1$ & $<0.001$ \\
\hline Stroke volume index $\left(\mathrm{ml} / \mathrm{m}^{2}\right)$ & $39.4 \pm 8.8$ & $51.5 \pm 11.0$ & $<0.001$ \\
\hline $\operatorname{LVEF}(\%)$ & $57.6 \pm 7.4$ & $62.8 \pm 7.5$ & $<0.001$ \\
\hline Peak gradient & $24.0 \pm 7.6$ & $38.7 \pm 13.6$ & $<0.001$ \\
\hline Mean gradient & $12.6 \pm 4.2$ & $19.8 \pm 8.3$ & $<0.001$ \\
\hline $\mathrm{EOA}\left(\mathrm{cm}^{2}\right)$ & $1.5 \pm 0.5$ & $2.1 \pm 0.7$ & $<0.001$ \\
\hline EOAi $\left(\mathrm{cm}^{2} / \mathrm{m}^{2}\right)$ & $0.84 \pm 0.26$ & $1.17 \pm 0.37$ & $<0.001$ \\
\hline DVI & $0.47 \pm 0.13$ & $0.66 \pm 0.20$ & $<0.001$ \\
\hline Severe PPM & $8(25 \%)$ & $1(3.1 \%)$ & $<0.001$ \\
\hline
\end{tabular}

LVEF: left ventricular ejection fraction; EOA(i): effective orifice area (index); DVI: dimensionless velocity index; PPM: prosthesis-patient mismatch. 
Table 3. Hemodynamic assessments during dobutamine stress echocardiography according to valve size.

\begin{tabular}{|c|c|c|c|c|}
\hline & & Rest & Exercise & $\mathbf{p}$ \\
\hline \multirow{5}{*}{ S } & Peak gradient & $28.6 \pm 6.7$ & $46.9 \pm 15.5$ & 0.002 \\
\hline & Mean gradient & $15.2 \pm 3.5$ & $24.2 \pm 9.3$ & 0.002 \\
\hline & EOA $\left(\mathrm{cm}^{2}\right)$ & $1.4 \pm 0.5$ & $2.0 \pm 0.8$ & 0.001 \\
\hline & $\operatorname{EOAi}\left(\mathrm{cm}^{2} / \mathrm{m}^{2}\right)$ & $0.83 \pm 0.32$ & $1.19 \pm 0.45$ & 0.001 \\
\hline & DVI & $0.48 \pm 0.19$ & $0.69 \pm 0.19$ & 0.001 \\
\hline \multirow{5}{*}{ M } & Peak gradient & $25.0 \pm 5.6$ & $36.9 \pm 9.6$ & 0.001 \\
\hline & Mean gradient & $12.9 \pm 3.0$ & $18.1 \pm 4.9$ & 0.005 \\
\hline & EOA $\left(\mathrm{cm}^{2}\right)$ & $1.5 \pm 0.3$ & $2.1 \pm 0.5$ & 0.006 \\
\hline & $\operatorname{EOAi}\left(\mathrm{cm}^{2} / \mathrm{m}^{2}\right)$ & $0.84 \pm 0.16$ & $1.21 \pm 0.30$ & 0.006 \\
\hline & DVI & $0.47 \pm 0.06$ & $0.68 \pm 0.18$ & 0.006 \\
\hline \multirow{5}{*}{$\mathrm{L}$} & Peak gradient & $19.8 \pm 8.0$ & $29.4 \pm 11.9$ & 0.001 \\
\hline & Mean gradient & $9.9 \pm 3.9$ & $14.8 \pm 7.4$ & 0.011 \\
\hline & EOA $\left(\mathrm{cm}^{2}\right)$ & $1.5 \pm 0.5$ & $2.0 \pm 0.9$ & 0.021 \\
\hline & $\operatorname{EOAi}\left(\mathrm{cm}^{2} / \mathrm{m}^{2}\right)$ & $0.86 \pm 0.30$ & $1.13 \pm 0.42$ & 0.016 \\
\hline & DVI & $0.47 \pm 0.12$ & $0.62 \pm 0.20$ & 0.014 \\
\hline \multirow{5}{*}{$\mathrm{XL}$} & Peak gradient & $20.0 \pm 7.7$ & $40.6 \pm 10.1$ & 0.002 \\
\hline & Mean gradient & $11.0 \pm 5.3$ & $22.2 \pm 8.9$ & 0.008 \\
\hline & EOA $\left(\mathrm{cm}^{2}\right)$ & $1.6 \pm 0.5$ & $2.1 \pm 0.5$ & 0.021 \\
\hline & EOAi $\left(\mathrm{cm}^{2} / \mathrm{m}^{2}\right)$ & $0.85 \pm 0.29$ & $1.10 \pm 0.28$ & 0.021 \\
\hline & DVI & $0.47 \pm 0.13$ & $0.62 \pm 0.11$ & 0.017 \\
\hline
\end{tabular}

EOA(i): effective orifice area (index); DVI: dimensionless velocity index. 
Table 4. Hemodynamic assessments during dobutamine stress echocardiography in patients with prosthesis-patient mismatch $(\mathrm{n}=8)$.

\begin{tabular}{lccc}
\hline & Rest & Exercise & p \\
\hline Peak gradient & $25.0 \pm 8.8$ & $40.0 \pm 16.5$ & 0.005 \\
Mean gradient & $13.0 \pm 4.5$ & $22.3 \pm 10.2$ & 0.004 \\
\hline EOA $\left(\mathrm{cm}^{2}\right)$ & & & \\
EOAi $\left(\mathrm{cm}^{2} / \mathrm{m}^{2}\right)$ & $1.0 \pm 0.1$ & $1.4 \pm 0.4$ & 0.005 \\
DVI & $0.58 \pm 0.05$ & $0.79 \pm 0.14$ & 0.003 \\
\hline
\end{tabular}

EOA(i): effective orifice area index; DVI: dimensionless velocity index; PPM: prosthesis-patient mismatch. 


\section{REFERENCES}

1. Rubino AS, Santarpino G, De Praetere H, Kasama K, Dalén M, Sartipy U, Lahtinen J, Heikkinen J, Deste W, Pollari F, Svenarud P, Meuris B, Fischlein T, Mignosa C, Biancari F. Early and intermediate outcome after aortic valve replacement with a sutureless bioprosthesis: Results of a multicenter study. J Thorac Cardiovasc Surg 2014;148:865-871.

2. Gilmanov D, Miceli A, Ferrarini M, Farneti P, Murzi M, Solinas M, Glauber M. Aortic valve replacement through right anterior minithoracotomy: can sutureless technology improve clinical outcomes? Ann Thorac Surg 2014;98:1585-1592.

3. Folliguet TA, Laborde F, Zannis K, Ghorayeb G, Haverich A, Shrestha M. Sutureless perceval aortic valve replacement: results of two European centers. Ann Thorac Surg 2012;93:1483-1488.

4. Gersak B, Fischlein T, Folliguet TA, Meuris B, Teoh KH, Moten SC, Solinas M, Miceli A, Oberwalder PJ, Rambaldini M, Bhatnagar G, Borger MA, Bouchard D, Bouchot O, Clark SC, Dapunt OE, Ferrarini M, Laufer G, Mignosa C, Millner R, Noirhomme P, Pfeiffer S, Ruyra-Baliarda X, Shrestha M, Suri RM, Troise G, Diegeler A, Laborde F, Laskar M, Najm HK, Glauber M. Sutureless, rapid deployment valves and stented bioprosthesis in aortic valve replacement: recommendations of an International Expert Consensus Panel. Eur J Cardiothorac Surg 2016;49:709-718.

5. Rockwood K, Song X, MacKnight C, Bergman H, Hogan DB, McDowell I, Mitnitski A. A global clinical measure of fitness and frailty in elderly people. CMAJ 2005;173:489-495

6. Izzat MB, Birdi I, Wilde P, Bryan AJ, Angelini GD. Evaluation of the hemodynamic performance of small CarboMedics aortic prostheses using dobutamine-stress Doppler echocardiography. Ann Thorac Surg 1995;60:1048-1052

7. Mertes H, Sawada SG, Ryan T, Segar DS, Kovacs R, Foltz J, Feigenbaum H. Symptoms, adverse effects, and complications associated with dobutamine stress echocardiography. Experience in 1118 patients. Circulation 1993;88:15-19.

8. Zoghbi WA, Chambers JB, Dumesnil JG, Foster E, Gottdiener JS, Grayburn PA, Khandheria BK, Levine RA, Marx GR, Miller FA Jr, Nakatani S, Quiñones MA, Rakowski H, Rodriguez LL, Swaminathan M, 
Waggoner AD, Weissman NJ, Zabalgoitia M; American Society of Echocardiography's Guidelines and Standards Committee; Task Force on Prosthetic Valves; American College of Cardiology Cardiovascular Imaging Committee; Cardiac Imaging Committee of the American Heart Association; European Association of Echocardiography; European Society of Cardiology; Japanese Society of Echocardiography; Canadian Society of Echocardiography; American College of Cardiology Foundation; American Heart Association; European Association of Echocardiography; European Society of Cardiology; Japanese Society of Echocardiography; Canadian Society of Echocardiography. Recommendations for evaluation of prosthetic valves with echocardiography and doppler ultrasound: a report From the American Society of Echocardiography's Guidelines and Standards Committee and the Task Force on Prosthetic Valves, developed in conjunction with the American College of Cardiology Cardiovascular Imaging Committee, Cardiac Imaging Committee of the American Heart Association, the European Association of Echocardiography, a registered branch of the European Society of Cardiology, the Japanese Society of Echocardiography and the Canadian Society of Echocardiography, endorsed by the American College of Cardiology Foundation, American Heart Association, European Association of Echocardiography, a registered branch of the European Society of Cardiology, the Japanese Society of Echocardiography, and Canadian Society of Echocardiography. J Am Soc Echocardiogr 2009;22:975-1014

9. Pibarot P, Dumesnil JG. Prosthesis-patient mismatch: definition, clinical impact, and prevention. Heart 2006;92:1022-1029.

10. Belluschi I, Moriggia S, Giacomini A, Del Forno B, Di Sanzo S, Blasio A, Scafuri A, Alfieri O. Can Perceval sutureless valve reduce the rate of patient-prosthesis mismatch? Eur J Cardiothorac Surg 2017;51:1093-1099.

11. Blais C, Dumesnil JG, Baillot R, Simard S, Doyle D, Pibarot P. Impact of valve prosthesis-patients mismatch on short-term mortality after aortic valve replacement. Circulation 2003;108:983-988.

12. Kadir I, Walsh C, Wilde P, Bryan AJ, Angelini GD. Comparison of exercise and dobutamine echocardiography in the haemodynamic assessment of small size mechanical aortic valve prostheses. Eur J Cardiothorac Surg 2002;21:692-697.

13. Garbi M, Chambers J, Vannan MA, Lancellotti P. Valve Stress Echocardiography: A Practical Guide for 
Referral, Procedure, Reporting, and Clinical Implementation of Results From the HAVEC Group. JACC Cardiovasc Imaging 2015;8:724-736.

14. Dalén M, Biancari F, Rubino AS, Santarpino G, De Praetere H, Kasama K, Juvonen T, Deste W, Pollari F, Meuris B, Fischlein T, Mignosa C, Gatti G, Pappalardo A, Sartipy U, Svenarud P. Ministernotomy versus full sternotomy aortic valve replacement with a sutureless bioprosthesis: a multicenter study. Ann Thorac Surg 2015;99:524-530.

15. Dalén M, Biancari F, Rubino AS, Santarpino G, Glaser N, De Praetere H, Kasama K, Juvonen T, Deste W, Pollari F, Meuris B, Fischlein T, Mignosa C, Gatti G, Pappalardo A, Svenarud P, Sartipy U. Aortic valve replacement through full sternotomy with a stented bioprosthesis versus minimally invasive sternotomy with a sutureless bioprosthesis. Eur J Cardiothorac Surg 2016;49:220-227.

16. Phan K, Tsai YC, Niranjan N, Bouchard D, Carrel TP, Dapunt OE, Eichstaedt HC, Fischlein T, Gersak B, Glauber M, Haverich A, Misfeld M, Oberwalder PJ, Santarpino G, Shrestha ML, Solinas M, Vola M, Yan TD, Di Eusanio M. Sutureless aortic valve replacement: a systematic review and meta-analysis. Ann Cardiothorac Surg 2015;4:100-111.

17. Laborde F, Fischlein T, Hakim-Meibodi K, Misfeld M, Carrel T, Zembala M, Madonna F, Meuris B, Haverich A, Shrestha M; Cavalier Trial Investigators. Clinical and haemodynamic outcomes in 658 patients receiving the Perceval sutureless aortic valve: early results from a prospective European multicentre study (the Cavalier Trial). Eur J Cardiothorac Surg 2016;49:978-986

18. Meuris B, Flameng WJ, Laborde F, Folliguet TA, Haverich A, Shrestha M. Five-year results of the pilot trial of a sutureless valve. J Thorac Cardiovasc Surg 2015;150:84-88.

19. Miceli A, Gilmanov D, Murzi M, Marchi F, Ferrarini M, Cerillo AG, Quaini E, Solinas M, Berti S, Glauber M. Minimally invasive aortic valve replacement with a sutureless valve through a right anterior mini-thoracotomy versus transcatheter aortic valve implantation in high-risk patients. Eur J Cardiothorac Surg 2016;49:960-965.

20. D’Onofrio A, Salizzoni S, Rubino AS, Besola L, Filippini C, Alfieri O, Colombo A, Agrifoglio M, Fischlein T, Rapetto F, Tarantini G, Svenarud P, Gabbieri D, Meuris B, Savini C, Gatti G, Aiello ML, Biancari F, Livi U, Stefano PL, Cassese M, Borrello B, Rinaldi M, Mignosa C, Gerosa G, on behalf of 
the ITER and SU-AVR Research Groups. The rise of new technologies for aortic valve stenosis: a comparison of sutureless and trans-catheter aortic valve implantation. J Thorac Cardiovasc Surg 2016;152:99-109.

21. Offstad J, Andersen K, Paulsson P, Andreasson J, Kjellman U, Lundblad O, Engstrøm KG, Haaverstad R, Svennevig JL. The Scandinavian multicenter hemodynamic evaluation of the SJM Regent aortic valve. J Cardiothorac Surg 2011;6:163.

22. Minardi G, Manzara C, Creazzo V, Maselli D, Casali G, Pulignano G, Musumeci F. Evaluation of 17-mm St. Jude Medical Regent prosthetic aortic heart valves by rest and dobutamine stress echocardiography. J Cardiothorac Surg. 2006 Sep 19;1:27

23. Sezai A, Kasamaki Y, Abe K, Hata M, Sekino H, Shimura K, Minami K. Assessment of the St. Jude Medical Regent prosthetic valve by continuous-wave Doppler and dobutamine stress echocardiography. Ann Thorac Surg 2010;89:87-92

24. Khoo JP, Davies JE, Ang KL, Galiñanes M, Chin DT. Differences in performance of five types of aortic valve prostheses: haemodynamic assessment by dobutamine stress echocardiography. Heart 2013;99:4147.

25. Repossini A, Rambaldini M, Lucchetti V, Da Col U, Cesari F, Mignosa C, Picano E, Glauber M. Early clinical and haemodynamic results after aortic valve replacement with the Freedom SOLO bioprosthesis (experience of Italian multicenter study). Eur J Cardiothorac Surg 2012;41:1104-1110.

26. Silberman S, Shaheen J, Merin O, Fink D, Shapira N, Liviatan-Strauss N, Bitran D. Exercise hemodynamics of aortic prostheses: comparison between stentless bioprostheses and mechanical valves. Ann Thorac Surg 2001;72:1217-1221.

27. Hanke T, Charitos EI, Paarmann H, Stierle U, Sievers HH. Haemodynamic performance of a new pericardial aortic bioprosthesis during exercise and recovery: comparison with pulmonary autograft, stentless aortic bioprosthesis and healthy control groups. Eur J Cardiothorac Surg 2013;44:e295-e301

28. Bach DS, Patel HJ, Kolias TJ, Deeb GM. Randomized comparison of exercise haemodynamics of Freestyle, Magna Ease and Trifecta bioprostheses after aortic valve replacement for severe aortic stenosis. Eur J Cardiothorac Surg 2016;50:361-367. 
29. Tasca G, Vismara R, MAngini A, Romagnoni C, Contino M, Redaelli A, Fiore GB, Antona C. Comparison of the performance of a sutureless bioprosthesis with two pericardial stented valves on small annuli: an in vitro study. Ann Thor Surg 2017;103:139-144.

30. Shrestha M, Maeding I, Höffler K, Koigeldiyev N, Marsch G, Siemeni T, Fleissner F, Haverich A. Aortic valve replacement in geriatric patients with small aortic roots: are sutureless valves the future? Interact Cardiovasc Thorac Surg 2013;17:778-782.

31. Dedeilias P, Baikoussis NG, Prappa E, Asvestas D, Argiriou M, Charitos C. Aortic valve replacement in elderly with small aortic root and low body surface area; the Perceval S valve and its impact in effective orifice area. J Cardiothorac Surg. 2016 Apr 11;11(1):54

32. Shalabi A, Spiegelstein D, Sternik L, Feinberg MS, Kogan A, Levin S, Orlov B, Nachum E, Lipey A, Raanani E. Sutureless Versus Stented Valve in Aortic Valve Replacement in Patients With Small Annulus. Ann Thorac Surg 2016;102:118-122.

33. Villa E, Messina A, Laborde F, Shrestha M, Troise G, Zannis K, Haverich A, Elfarra M, Folliguet T. Challenge for perceval: aortic valve replacement with small sutureless valves - a multicenter study. Ann Thorac Surg 2015;99:1248-1254.

34. Shrestha M. Do we need sutureless or self-anchoring aortic valve prostheses? Ann Cardiothorac Surg 2015;4:175-177. 